\title{
Construction of Metal-Organic Frameworks with Various Zinc-Tetrazolate Nanotubes
}

Yayong Sun, ${ }^{\mathrm{ab}}$ Dong-Fei Lu, ${ }^{\mathrm{a}}$ Kechen Wu, ${ }^{\mathrm{c}}$ Tianhua Zhou, ${ }^{\mathrm{a}}$ Fei Wang, ${ }^{\mathrm{a}}$ Jian Zhang ${ }^{\mathrm{a}}$

a State Key Laboratory of Structural Chemistry, Fujian Institute of Research on the Structure of Matter, Chinese Academy of Sciences, Fuzhou, Fujian 350002, P. R. China. E-mail: wangfei04@fjirsm.ac.cn; zhj@fjirsm.ac.cn.

${ }^{\mathrm{b}}$ University of Chinese Academy of Sciences, Beijing 100049, P. R. China.

${ }^{c}$ Fujian Key Laboratory of Functional Marine Sensing Materials, Minjiang University.

\section{Materials and General Procedures.}

Materials and Instrumentation. All reagents were purchased commercially and used without further purification. All of the chemicals are commercial available, and used without further purification. Elemental analyses of $\mathrm{C}$ and $\mathrm{H}$ were performed with an EA1110 CHNS-0 CE elemental analyzer. The IR (KBr pellet) spectra were recorded (400-4000 $\mathrm{cm}^{-1}$ region) on a SpectrumOne FT-IR spectrometer. Thermogravimetric analyses (TGA) was carried out in an $\mathrm{N}_{2}$ atmosphere with a heating rate of $10{ }^{\circ} \mathrm{C} / \mathrm{min}$ on a STA449C integration thermal analyzer. Powder X-ray diffraction (PXRD) data were collected on a Rigaku MultiFlex diffractometer using $\mathrm{Cu} K_{\alpha}$ radiation. The UV-vis absorbance of supernatant solutions was monitored periodically using a Lambda 365 spectrometer.

\section{X-ray Crystallography.}

Single-crystal XRD data of compounds $\mathbf{1}$ and $\mathbf{2}$ were collected on a Bruker P4 single-crystal X-ray diffractometer (Mo $K_{\alpha}$ radiation, $\lambda=0.71073 \AA$ ). Single-crystal XRD data of compound 3 was collected on a SuperNova with four-circle diffractometer at 102(6) K equipped with a mirror-monochromated GaK $\backslash \mathrm{a}$ radiation $(\lambda=1.54184 \AA)$. The multi-scan program was applied for the empirical absorption correction. ${ }^{1}$ The structure was solved by using SHELXT ${ }^{2}$ and refined with SHELXL ${ }^{3}$ using OLEX2. ${ }^{4}$ The SQUEEZE routine of PLATON ${ }^{5}$ was used to remove the highly disordered solvent species in the voids.

\section{Synthesis.}

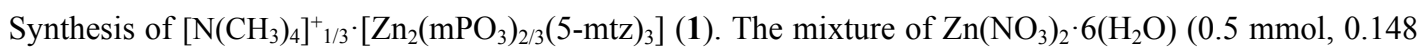
g), 5-Hmtz (0.5 mmol, $0.042 \mathrm{~g})$, methyl phosphoric acid $(0.5 \mathrm{mmol}, 0.0605 \mathrm{~g})$, three drops of tetramethylammonium hydroxide $(25 \mathrm{wt} \%$ ) and $5 \mathrm{~mL}$ DMF were sealed in a $20 \mathrm{~mL}$ vial and heated to 120 ${ }^{\circ} \mathrm{C}$ for 4 days. Colorless rod crystals of the product were formed and collected by filtration and then washed with DMF several times (yield: $45 \%$ based on $\mathrm{Zn}$ ). Anal. calcd for $\mathrm{C}_{8} \mathrm{H}_{15} \mathrm{~N}_{12.33} \mathrm{O}_{2} \mathrm{P}_{0.66} \mathrm{Zn}_{2}, \mathrm{C}, 20.54 ; \mathrm{H}, 3.21$; N, 36.94\%. Found: C, 20.29; H, 3.34; N, $36.84 \%$.

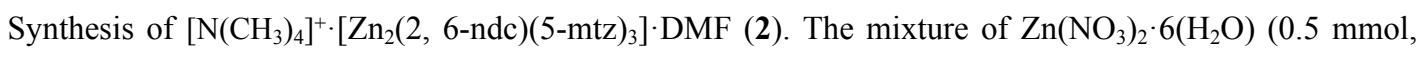
$0.148 \mathrm{~g}), 5$-Hmtz (0.5 mmol, $0.042 \mathrm{~g}), 2$, 6-naphthalenedicarboxylic acid $(0.5 \mathrm{mmol}, 0.1051 \mathrm{~g})$, one drop of tetramethylammonium hydroxide $(25 \mathrm{wt} \%$ ) and $5 \mathrm{~mL}$ DMF were sealed in a $20 \mathrm{~mL}$ vial and heated to 120 ${ }^{\circ} \mathrm{C}$ for 12 hours. Colorless rod crystals of the product were formed and collected by filtration and then washed with DMF several times (yield: $75 \%$ based on $\mathrm{Zn}$ ). $\mathrm{C}_{25} \mathrm{H}_{34} \mathrm{~N}_{14} \mathrm{O}_{5} \mathrm{Zn}_{2}, \mathrm{C}, 40.48 ; \mathrm{H}, 4.59$; N, 26.44\%. 
Found: C, 39.64; H, 4.54; N, 26.07\%.

Synthesis of $\left[\mathrm{N}\left(\mathrm{CH}_{3}\right)_{4}\right]^{+} \cdot\left[\mathrm{Zn}_{2} \text { (atipa)(5-mtz) }\right)_{3} \cdot 2 \mathrm{DMF}$ (3). The mixture of $\mathrm{Zn}\left(\mathrm{NO}_{3}\right)_{2} \cdot 6\left(\mathrm{H}_{2} \mathrm{O}\right)(0.5 \mathrm{mmol}$, $0.148 \mathrm{~g}$ ), 5-Hmtz (0.5 mmol, $0.042 \mathrm{~g})$, 5-amino-2,4,6-triiodoisophthalic acid (0.2 mmol, $0.1116 \mathrm{~g})$, one drop of tetramethylammonium hydroxide (25 wt\%) and $5 \mathrm{~mL}$ DMF were sealed in a $20 \mathrm{~mL}$ vial and heated to 120 ${ }^{\circ} \mathrm{C}$ for 3 days. Rod crystals of the product were formed and collected by filtration and then washed with DMF several times (yield: $83 \%$ based on $\mathrm{Zn}$ ). $\mathrm{C}_{24} \mathrm{H}_{35} \mathrm{~N}_{16} \mathrm{O}_{6} \mathrm{I}_{3} \mathrm{Zn}_{2}, \mathrm{C}, 24.95 ; \mathrm{H}, 3.03 ; \mathrm{N}, 19.40 \%$. Found: C, $24.11 ; \mathrm{H}, 3.24 ; \mathrm{N}, 19.61 \%$.

\section{Iodine/Cyclohexane adsorption measurement and release of $I_{2}$ in ethanol solution.}

Adsorption studies were conducted via adding $40 \mathrm{mg}$ of 1 in $4 \mathrm{~mL}$ of a $0.01 \mathrm{M}$ iodine/cyclohexane solution in a sealed vial at ambient temperature. After $96 \mathrm{~h}$, the $\mathrm{I}_{2}$-loaded single crystals were collected and dryed at room temperature, then placed in $10 \mathrm{~mL}$ of ethanol, and the $\mathrm{I}_{2}$ content was estimated by UV-vis spectroscopy with time.

Iodine Vapor Adsorption Measurement. An open vial containing $40 \mathrm{mg}$ of $\mathbf{1}$ and two grain of iodine were sealed in a $20 \mathrm{~mL}$ glass vessel, which was subsequently placed in an oven at $80{ }^{\circ} \mathrm{C}$. The vial containing the $\mathrm{I}_{2}$ adsorbed sample was weighed periodically until the mass of it remained unchanged.

\section{Selective adsorption of cationic dyes in 1.}

As-synthesized $1(120 \mathrm{mg})$ was immersed in an aqueous solution $(10 \mathrm{~mL})$ of methylene blue (MB) $(25$ $\mathrm{mg} / \mathrm{L}$ ) at room temperature for $24 \mathrm{~h}$. The cation exchange process was monitored by liquid UV-vis spectroscopy based on typical absorption of MB. The aqueous solution of MB was pipetted at different time interval to measure the UV-vis adsorption intensity. After cation exchange, the crystals were filtered, rinsed with deionized water and dried in the air. The UV-vis absorbance at maximum wavelength of $\mathrm{MB}\left(\lambda_{\max }=\right.$ $665 \mathrm{~nm}$ ) was selected to calculate the MB concentration, and the absorbance value of the solution before adsorption was normalized to $100 \%$. The removal rates $(R)$ were calculated using $R=\left(C_{0}-C_{\mathrm{t}}\right) / C 0 \times 100 \%$ (where $C_{0}$ is the initial concentration and $C_{\mathrm{t}}$ is the concentration at time $t$ ). 
Table S1. Crystal Data and Structure Refinements for Compounds 1-3.

\begin{tabular}{|c|c|c|c|}
\hline & Compound 1 & Compound 2 & Compound 3 \\
\hline Empirical formula & $\mathrm{C}_{8} \mathrm{H}_{15} \mathrm{~N}_{12.33} \mathrm{O}_{2} \mathrm{P}_{0.66} \mathrm{Zn}_{2}$ & $\mathrm{C}_{25} \mathrm{H}_{34} \mathrm{~N}_{14} \mathrm{O}_{5} \mathrm{Zn}_{2}$ & $\mathrm{C}_{24} \mathrm{H}_{35} \mathrm{~N}_{16} \mathrm{O}_{6} \mathrm{I}_{3} \mathrm{Zn}_{2}$ \\
\hline Formula weight & 467.33 & 741.16 & 1154.46 \\
\hline Temperature/K & $293(2)$ & $293(2)$ & $100.01(1)$ \\
\hline Crystal system & hexagonal & hexagonal & tetragonal \\
\hline Space group & $P 6_{3} / m$ & $P 6_{3} / m$ & $P 4 / m b c$ \\
\hline$a / \AA$ & $14(2)$ & $24(1)$ & $32(4)$ \\
\hline$b / \AA ̊$ & $14(2)$ & $24(1)$ & $32(4)$ \\
\hline$c / \AA$ & $17(4)$ & $17(2)$ & $16(5)$ \\
\hline$\alpha /^{\circ}$ & 90 & 90 & 90 \\
\hline$\beta /{ }^{\circ}$ & 90 & 90 & 90 \\
\hline$\gamma /{ }^{\circ}$ & 120 & 120 & 90 \\
\hline$V / \AA^{3}$ & $3183.6(1)$ & $8479(11997)$ & $16740.0(7)$ \\
\hline$Z$ & 12 & 12 & 8 \\
\hline$\rho c a l c g / c m 3$ & 1.385 & 0.698 & 1.545 \\
\hline$\mu / \mathrm{mm}-1$ & 2.333 & 0.870 & 19.095 \\
\hline$F(000)$ & 1326.0 & 1794.0 & 7312.0 \\
\hline Rint & 0.0368 & 0.1248 & 0.0459 \\
\hline Data/restraints/parameters & $2517 / 0 / 112$ & $5053 / 0 / 167$ & $9015 / 24 / 371$ \\
\hline$S$ & 1.324 & 1.622 & 1.088 \\
\hline$R_{1}, w R_{2}[\mathrm{I}>=2 \sigma(\mathrm{I})]^{a}$ & $R_{1}=0.0595, w R_{2}=0.1796$ & $\begin{array}{l}R_{1}=0.1481, w R_{2}= \\
0.4299\end{array}$ & $R_{1}=0.0845, w R_{2}=0.2139$ \\
\hline$R_{1}, w R_{2}[\text { all data }]^{b}$ & $R_{1}=0.0605, w R_{2}=0.1805$ & $\begin{array}{l}R_{1}=0.1688, w R_{2}= \\
0.4529\end{array}$ & $R_{1}=0.1042, w R_{2}=0.2297$ \\
\hline CCDC No. & 2005223 & 2005224 & 2005225 \\
\hline
\end{tabular}

${ }^{a} R_{1}=\Sigma\left(\left|F_{o}\right|-\mid F_{c}\right) / \Sigma\left|F_{o}\right| ;{ }^{b} w R_{2}=\left\{\Sigma\left[w\left(F_{o 2}-F_{c 2}\right)_{2}\right] / \Sigma\left[w\left(F_{o 2}\right)_{2}\right]\right\}_{1 / 2}$

(a)

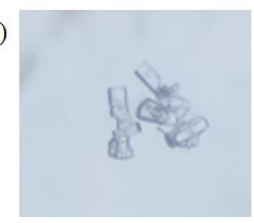

(b)

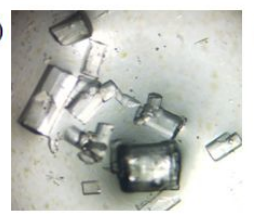

(c)

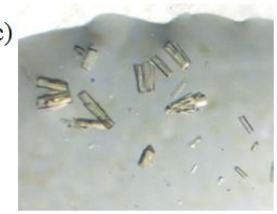

Figure S1. The optical micrographs of single crystals: (a), compound 1; (b), compound $\mathbf{2}$ and (c), compound $\mathbf{3}$.
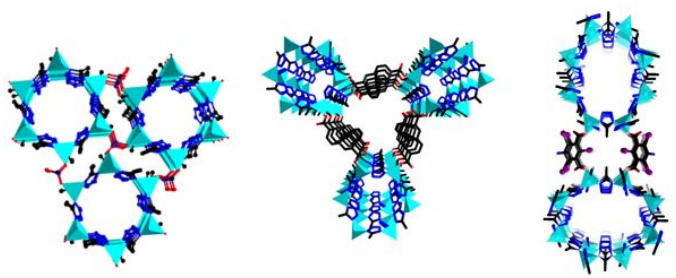

Figure S2. Connection modes of Zn-tetrazolate tubes with different organic molecules. 


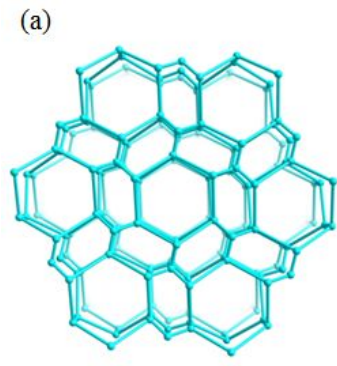

(b)

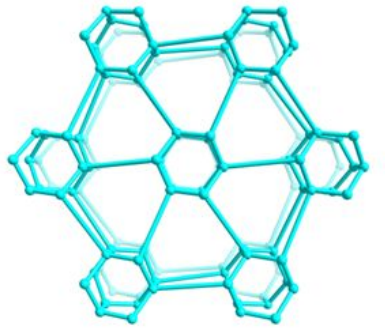

(c)

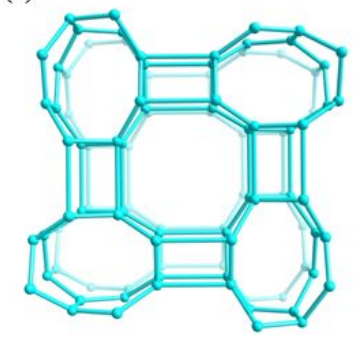

Figure S3. Topological network of 1 (a), 2 (b) and 3 (c).

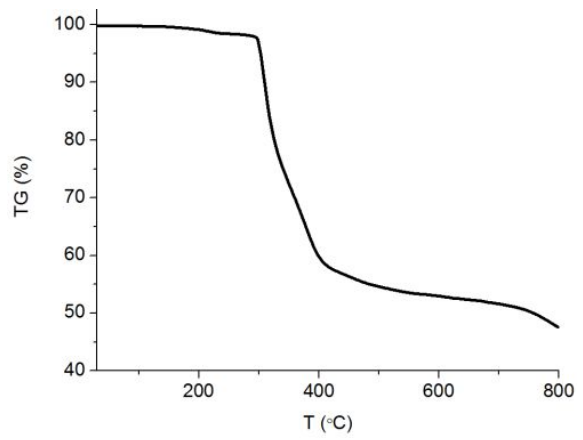

Figure S4. The TGA curve of Compound 1.

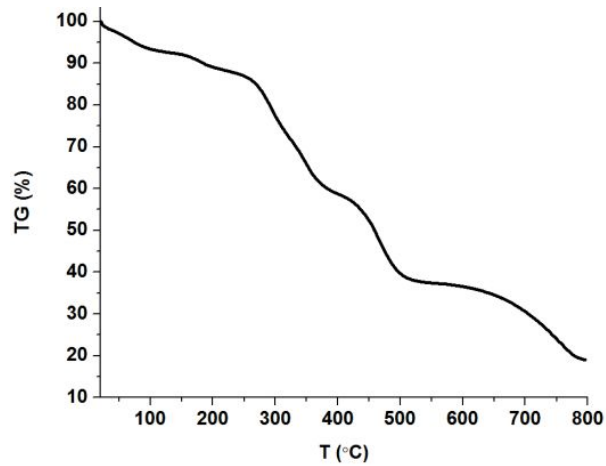

Figure S5. The TGA curve of compound 2. The powder XRD and TGA results show that compound $\mathbf{2}$ has poor stability.

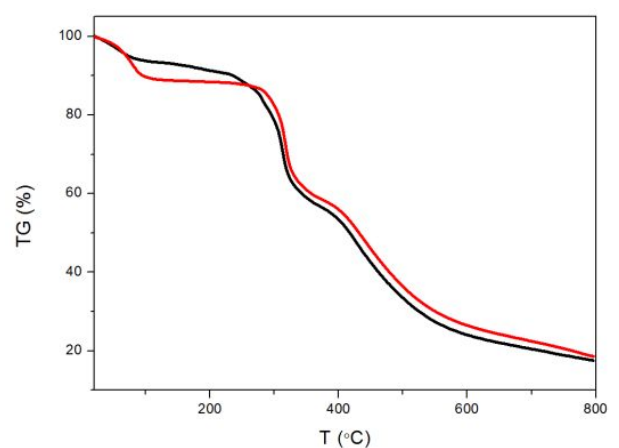

Figure S6. The TGA curves of compound 3 and after exchanged by EtOH. 


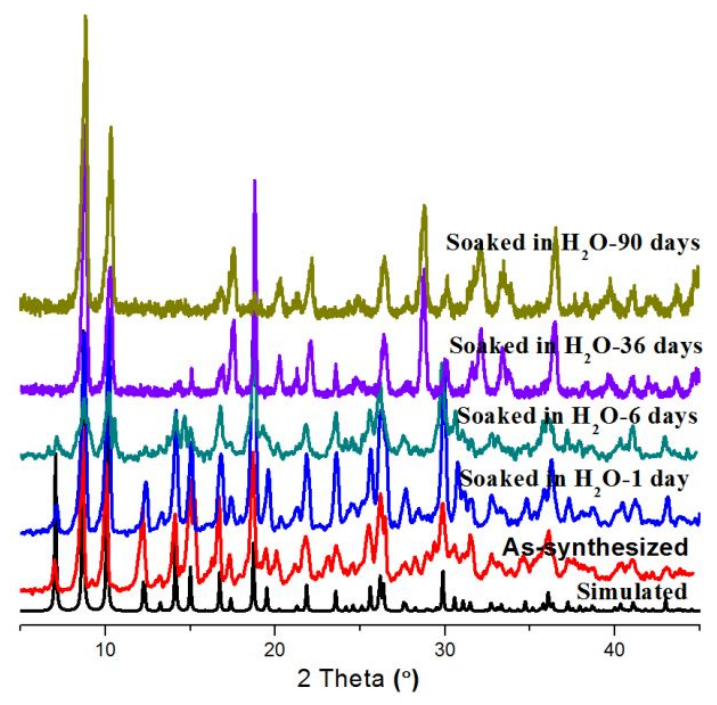

Figure S7. The PXRD of 1 soaked in water for different times.

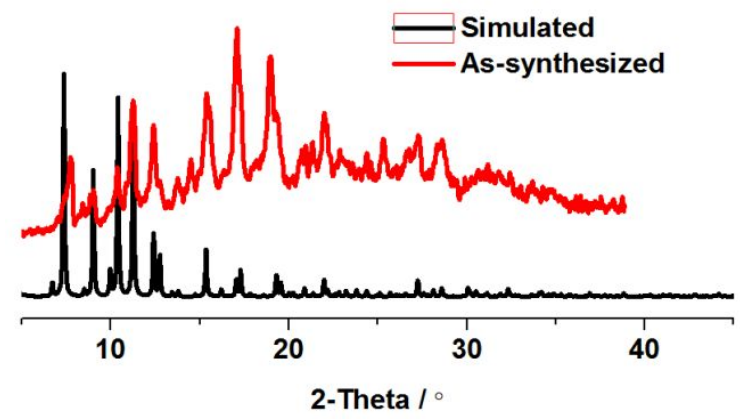

Figure S8. The PXRD patterns of compound 2.

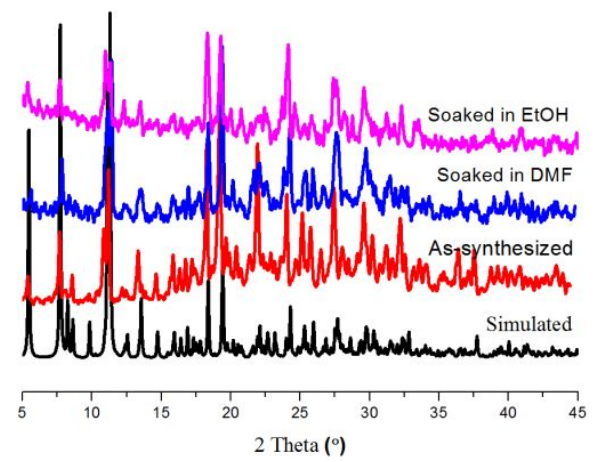

Figure S9. The PXRD patterns of compound $\mathbf{3}$ soaked in different solvents for three days.

Powder XRD and TGA results showed that compound 3 can maintain the framework after solvent exchange (Figure S4 and S10), however, the framework collapsed once the solvent was removed. Therefore, the porosity of $\mathbf{3}$ was not researched. 
(a)

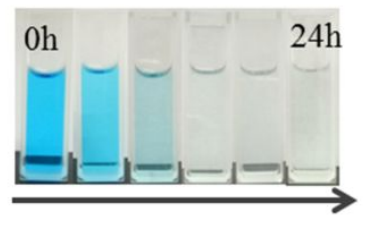

(c)

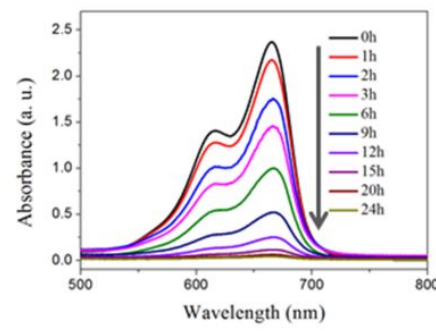

(b)

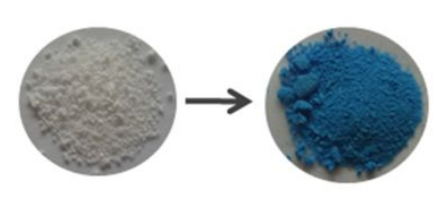

(d)

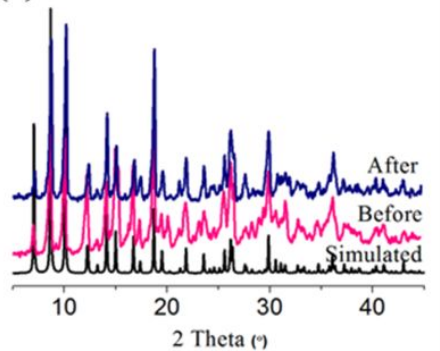

Figure S10. (a) The solution color change with time. (b) Photos of 1 before and after the adsorption of MB. (c) UV-vis spectra of water solutions containing MB with time. (d) PXRD patterns of 1 before and after capturing MB.

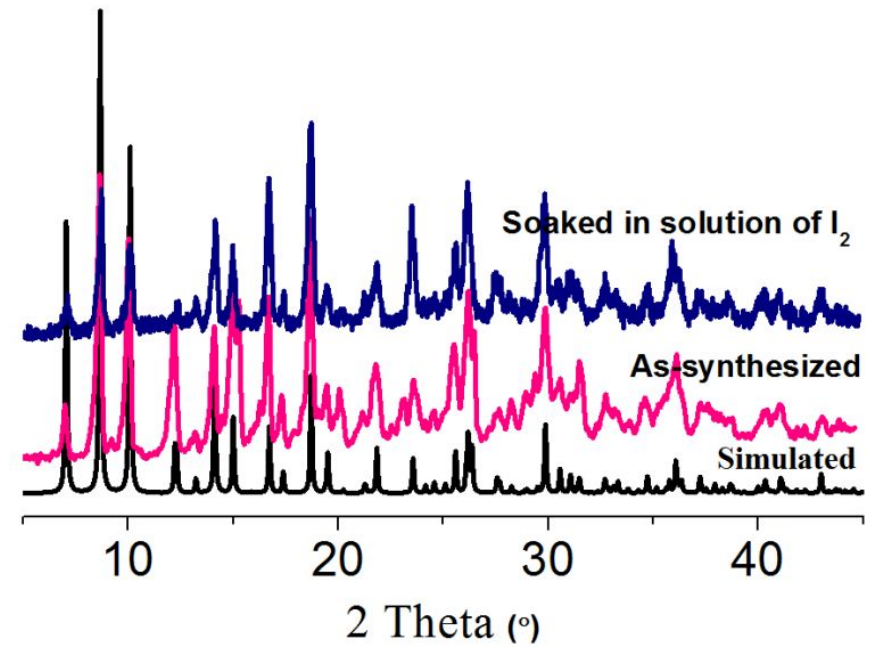

Figure S11. PXRD patterns of 1 and soaked in solution of $I_{2}$. 

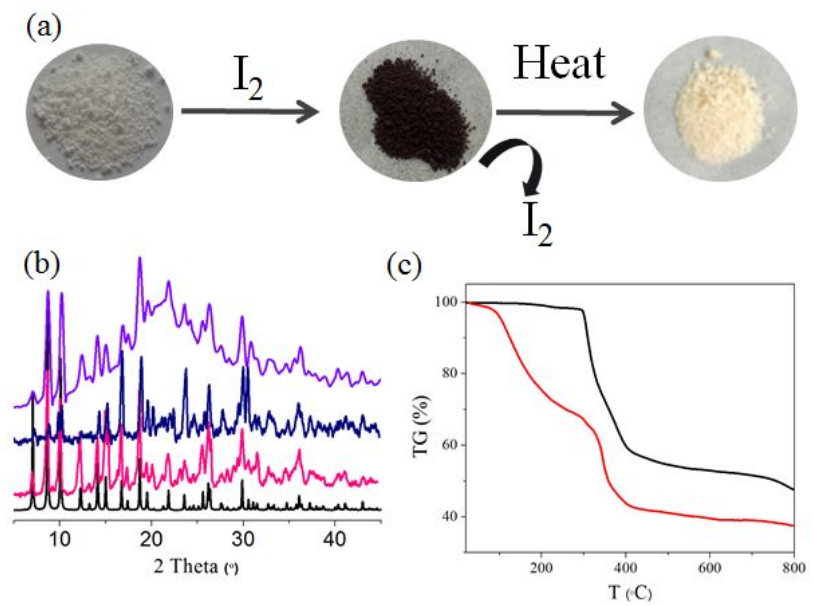

Figure S12. (a) The crystal color change of 1 after loading and downloading iodine. (b) Simulated (black), As-synthesized (peach) PXRD patterns of 1 before (pink) and after (dark blue) loading and downloading (blue) iodine. (c) TGA curves of $\mathbf{1}$ before (black) and after (red) loading iodine.

(1) Sheldrick, G.-M. SHELXT-Integrated space-group and crystal-structure determination. Acta Crystallogr., Sect. A: Found. Adv. 2015, 71, 3-8.

(2) Sheldrick, G.-M. Crystal structure refinement with SHELXL. Acta Crystallogr., Sect. C: Struct. Chem. 2015, 71, 3-8.

(3) Dolomanov, O.-V.; Bourhis, L.-J.; Gildea, R.-J.; Howard, J.-A. K.; Puschmann, H. OLEX2: a complete structure solution, refinement and analysis program. J. Appl. Crystallogr. 2009, 42, 339-341.

(4) Spek, A.-L. PLATON SQUEEZE: a tool for the calculation of the disordered solvent contribution to the calculated structure factors. Acta Crystallogr., Sect. C: Struct. Chem. 2015, 71, 9-18.

(5) Spek, A.-L. Program PLATON. J. Appl. Crystallogr. 2003, 36, 7-13. 